\title{
Synthesis and energy transfer in original poly(3-alkylthiophene)-g- poly(fluorene) toothbrush copolymers
}

\author{
Joost Steverlynck $^{1}$, Julien De Winter ${ }^{2}$, Pascal Gerbaux ${ }^{2}$, Guy Koeckelberghs ${ }^{1}$
}

J. Steverlynck, Prof. G. Koeckelberghs

${ }^{1}$ Laboratory for Polymer Synthesis, KU Leuven, Celestijnenlaan 200F, B-3001 Heverlee, BELGIUM

E-mail: guy.koeckelberghs@chem.kuleuven.be

Dr. J. De Winter, Prof. P. Gerbaux,

${ }^{2}$ Organic Synthesis and Mass Spectrometry Laboratory, Interdisciplinary Center for Mass Spectrometry, University of Mons-UMONS, 23 Place du Parc, 7000 Mons, BELGIUM

\section{Keywords}

conjugated polymers; block copolymers; self-assembly; fluorescence; graft copolymers

\begin{abstract}
Conjugated tootbrush copolymers are prepared by connecting end-capped poly $\left(9,9^{\prime}-\right.$ dioctylfluorene) (PF) side-chains (PF) to a poly(3-alkylthiophene) (P3AT) backbone via the CuAAC reaction. The ratio of grafted/nongrafted segment is varied. The influence of the covalent attachment of sidechains to the backbone on the self-assembly is studied by UV-vis spectroscopy. By excitation of the PF side-chains energy transfer to the P3HT backbone is studied.
\end{abstract}

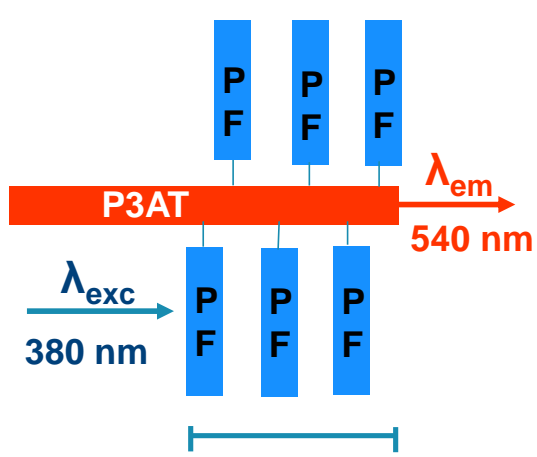

$Y=0,8,49,71,100 \%$ 


\section{Introduction}

The domain of conjugated polymers with 2D topologies is slowly developing. The majority of the reported polymers are (hyper)branched conjugated polymers. ${ }^{1-8}$ There are some reports of conjugated graft copolymers and only one about a conjugated star copolymer. ${ }^{9-13}$ Whereas conjugated graft copolymers already represent a very interesting architecture, the topology can be made even more advanced by adding a linear non-grafted segment to the backbone in order to form toothbrush (co)polymers. In the field of non-conjugated polymers, the properties of these toothbrush copolymers are already exploited. ${ }^{14-17}$ Block copolymers have been already demonstrated to be interesting drug carrier systems upon micelle formation. Nowadays, the versatility of the architecture of toothbrush-like polymers is exploited to optimize drug delivery systems. A whole range of macromolecular parameters can be optimized. For instance, parameters such as the linear vs brush segment ratio, the length of the grafted sidechain, the possibility to introduce multicomponent grafts, the grafting density... can be tuned. Conjugated polymers are mainly exploited for their optical properties, which depend on their molecular and supramolecular structures. By selecting the molecular structures of the backbone and the sidechains, broadband absorbance or energy funneling can be tuned. However, due to the presence of sidechains the self-assembly of the backbone by $\pi$ - $\pi$-interactions will be compromised. Making use of the unique structure of toothbrush (co)polymers, this selfassembly can be tuned by changing the ratio of non-grafted vs grafted blocks. For the nongrafted parts, interaction will be much easier due to absence of polymer sidechains. In the present paper, we report the synthesis of original P3AT-g-PF toothbrush polymers with variation of the length of non-grafted vs grafted parts. Poly(3-alkylthiophene) (P3AT) homopolymer is known for its high self-assembly propensity, whereas the emission spectrum of the poly(fluorene) (PF) sidechains is known to overlap with the absorption spectrum of the P3AT backbone. 


\section{Results and discussion}

\subsection{Synthesis and characterization of the homo and block (co)polymers}

For the preparation of the P3AT backbones, the controlled Kumada catalyst transfer condensative polymerization (KCTCP) is employed. Using an $o$-tolyl external initiator $(\mathbf{1})^{18}$, this method allows for the synthesis of AB block copolymers in a controlled way (Scheme 1). In a first step, the hexylthiophene monomer (3), after conversion of the premonomer (2) via Grignard metathesis (GRIM), is polymerized to form the $\mathrm{X}$ block. In a next step, the thiophene monomer with bromohexyl sidechain (5), after activation of the premonomer (4) via GRIM, is added, forming the $\mathrm{Y}$ block. We target polymers with DP $=40$ and percentage of the $\mathrm{Y}$ block of $0,25,50,75$ and $100 \%$ (ratio of the number of monomer units).

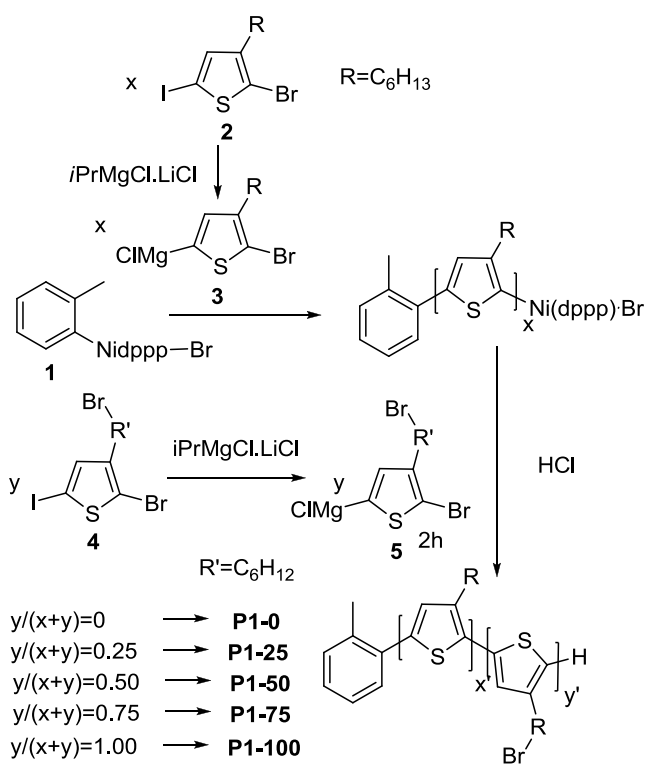

Scheme 1. Synthesis of poly(thiophene) homo and block copolymers P1-0/25/50/75/100 for the toothbrush polymer backbone.

$\bar{M}_{\mathrm{n}}$ and $Đ$, obtained via GPC, are listed in Table 1. The dispersities were measured around 1.1, whereas the $\bar{M}_{\mathrm{n}}$ values lie within the same range, between 5000 and $7000 \mathrm{~g} / \mathrm{mol}$. DP estimation was also performed using ${ }^{1} \mathrm{H}-\mathrm{NMR}$ (Figure 1). Signal a corresponds to the protons of the $o$ tolyl group on the initiator. Signal b corresponds to the $\alpha-\mathrm{CH}_{2}$ of the internal thiophene units, while signal c corresponds to the $\alpha-\mathrm{CH}_{2}$ of the terminal thiophene containing a hydrogen atom as the end-group. No signal of Br-terminated chains, resonating at $2.52 \mathrm{ppm},{ }^{19}$ were observed. 
Signal d corresponds to the $\mathrm{CH}_{2}$ protons next to the bromine atom in the bromohexyl sidechains.

The non $3 / 2$ ratio for a to $\mathrm{c}$ protons may be attributed to protonated monomers acting as initiator leading to $\mathrm{H} / \mathrm{H}$ terminated polymers.

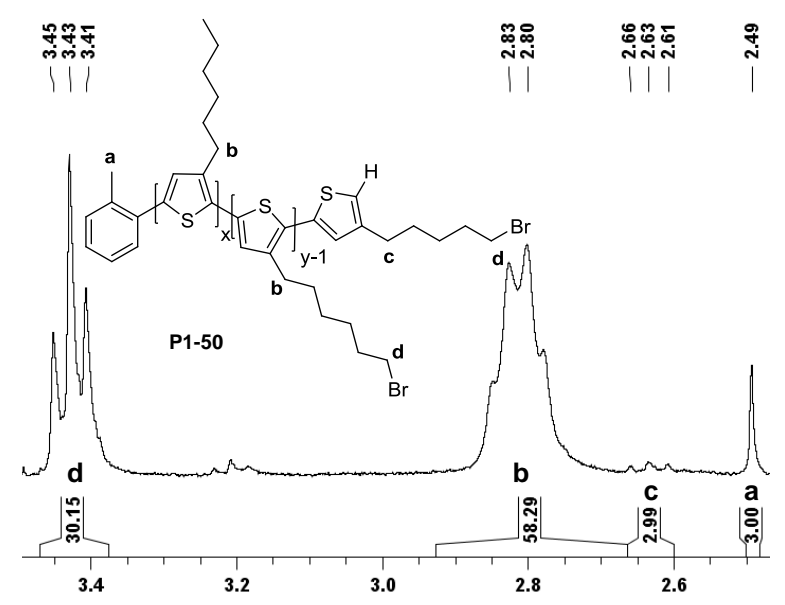

Figure 1. ${ }^{1} \mathrm{H}-\mathrm{NMR}$ analysis of P1-50 for DP and \% functionalization estimation.

The DP can then be calculated by dividing all units by half of the terminal units using the following formula: $D P=\frac{b+c}{\frac{c}{2}+\frac{a}{3}}$. The percentage of the Y block (Table 1) compared to the total length is calculated as follow: $\%($ blockY $)=\frac{d}{b+c} * 100$.

Table 1. GPC and ${ }^{1} \mathrm{H}-\mathrm{NMR}$ analysis of $\mathbf{P 1 - 0 / 2 5 / 5 0 / 7 5 / 1 0 0}$.

\begin{tabular}{ccccccc}
\hline Polymer & $\begin{array}{c}\overline{\boldsymbol{M}}_{\mathbf{n}} \\
(\mathbf{k g} / \mathbf{m o l})\end{array}$ & Ð & DP & $\begin{array}{c}\text { Y block } \\
(\%)\end{array}$ & $\begin{array}{c}\text { X block } \\
\text { (units })\end{array}$ & $\begin{array}{c}\text { Y block } \\
\text { (units) }\end{array}$ \\
\hline P1-0 & 7.7 & 1.1 & 26 & 0 & 26 & 0 \\
P1-25 & 6.2 & 1.2 & 22 & 8 & 20 & 2 \\
P1-50 & 6.1 & 1.2 & 25 & 49 & 12 & 12 \\
P1-75 & 6.2 & 1.1 & 25 & 71 & 7 & 18 \\
P1-100 & 5.9 & 1.1 & 24 & 100 & 0 & 24
\end{tabular}

The percentages of the Y block are close to the targeted values, except for P1-25, only having a percentage of 8 .

In a postpolymerization step, the bromo groups are substituted for azide groups (Scheme 2). ${ }^{20}$ The reaction was monitored via ${ }^{1} \mathrm{H}-\mathrm{NMR}$ (Figure 2) and IR-spectroscopy (see SI). The peaks 
of the $\mathrm{CH}_{2}$ protons next to the bromine atom shift from around 3.4 to $3.3 \mathrm{pm}$. In the IR spectrum, a significant peak around $2085 \mathrm{~cm}^{-1}$ appears. A complete conversion was realized.

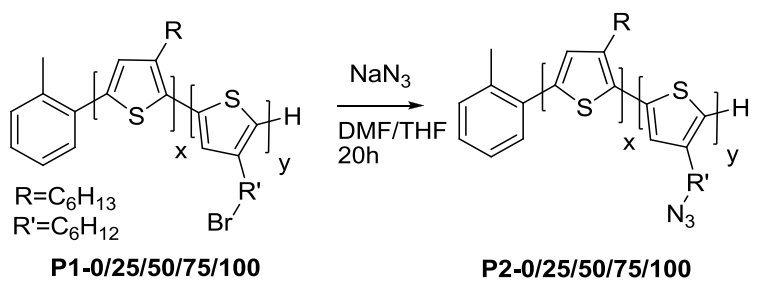

Scheme 2. Postpolymerization reaction for conversion of $\mathbf{P 1 - x}$ to $\mathbf{P 2 - x}$ by $\mathrm{Br}_{-} \mathrm{N}_{3}$ exchange.
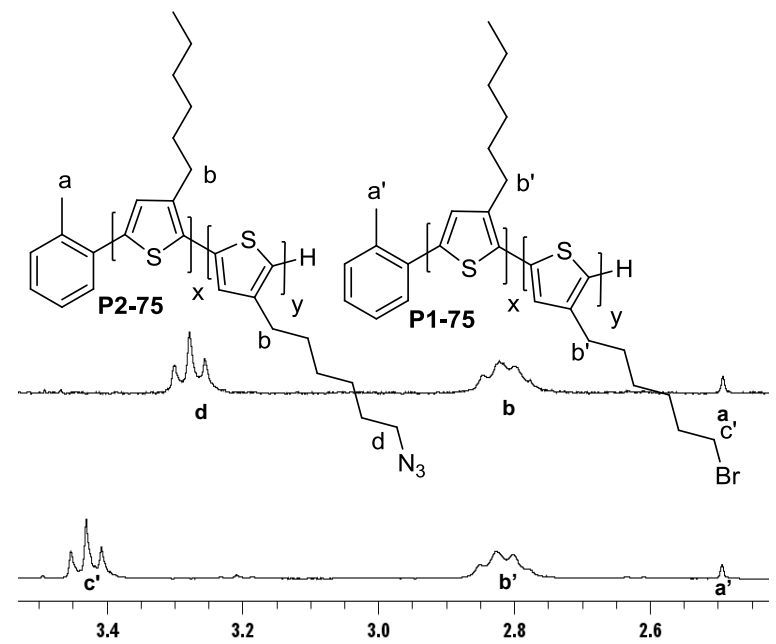

Figure 2. ${ }^{1} \mathrm{H}-\mathrm{NMR}$ analysis for conversion of P1-75 to P2-75

The polyfluorene polymers that will be grafted to the backbone were prepared using the SuzukiMiyaura catalyst transfer condensative polymerization. To avoid problems with stability of the standard catalyst/initiator $\mathrm{PhPd}(t \mathrm{Bu})_{3} \mathrm{Br}$, we opted for a stable $t \mathrm{Bu} 3 \mathrm{P}$-coordinated 2phenylaniline-based palladacycle complex (6) as the precatalyst. ${ }^{21-24}$ This catalyst was activated in basic medium in presence of $\mathrm{PhBr}$. After addition of monomer 7 and 3 hours of reaction, the polymerization is quenched with an endcapper bearing a terminal hydroxyl group (Scheme 3). 

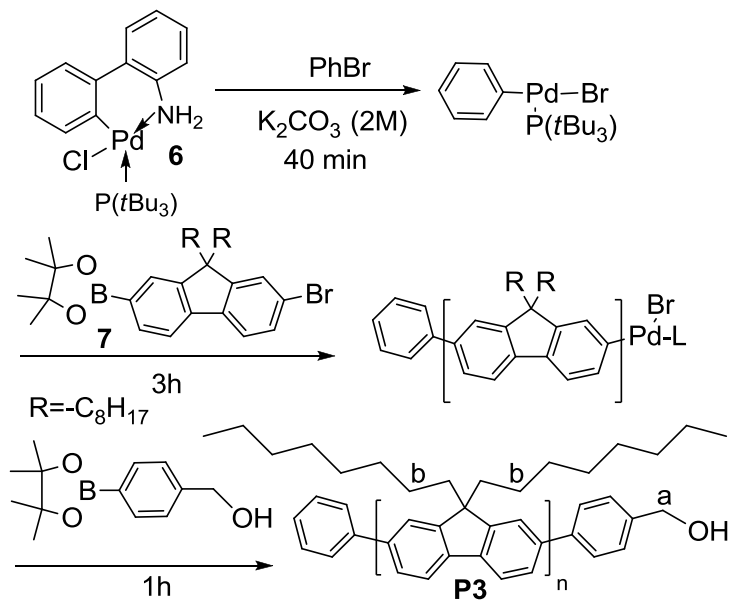

Scheme 3. Synthesis of $\mathbf{P 3}$.

The low dispersity of 1.2 is a first indication of the controlled nature of the polymerization (Table 2). The controlled nature of the polymerization was further confirmed using MALDIToF analysis. The MALDI-ToF spectrum shows only peaks which can be assigned to polymers that contain end-groups corresponding to the initiator and end-capper $(77+n .388 .6+107)$, confirming the controlled nature of the polymerization with the palladacycle precatalyst (Figure 3). Then, we determined the DP $=15$ using ${ }^{1} \mathrm{H}-\mathrm{NMR}$ peaks of $\mathrm{CH}_{2}$ protons of the end-capper (Scheme $3, \mathrm{SI}$ ), by calculating $\frac{\frac{b}{4}}{\frac{a}{2}}$. This value is close to the value of 14 calculated using the $\bar{M}_{\mathrm{n}}$ value from GPC (Table 2), taking into account the correction factor determined by the group of Wang. ${ }^{25}$

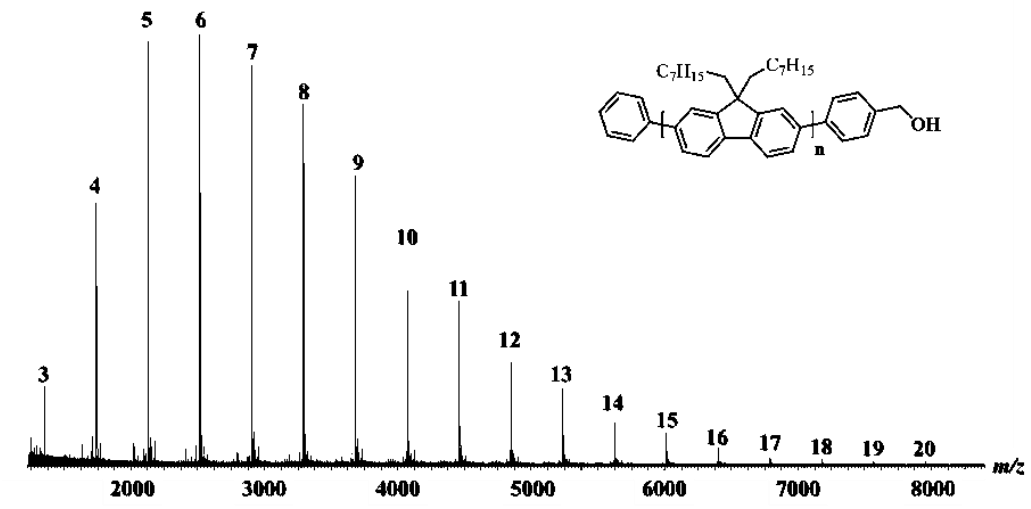

Figure 3. MALDI-ToF spectrum of $\mathbf{P 3}$ (degree of polymerization is assigned on the top of each signal) 
The terminal acetylene was introduced by end-capping with end-capper containing a terminal $\mathrm{OH}$ function followed by a postpolymerization esterification reaction with hexynoic acid (Scheme 4) in the presence of $N, N^{\prime}$-4-dimthylaminopyridine (DMAP) and $N, N^{\prime}$-dicyclohexyl carbodiimide (DCC). Using directly a conjugated terminal acetylene as end-capper was not an option as this leads to disproportionation.
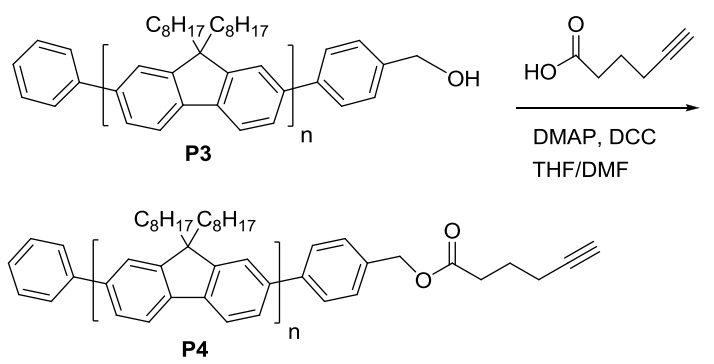

Scheme 4. Postpolymerization esterification of $\mathbf{P 3}$ to $\mathbf{P 4}$.

Complete conversion to $\mathbf{P 4}$ was confirmed by MALDI-ToF (Figure 4) and ${ }^{1} \mathrm{H}-\mathrm{NMR}$ (Figure $5)$.

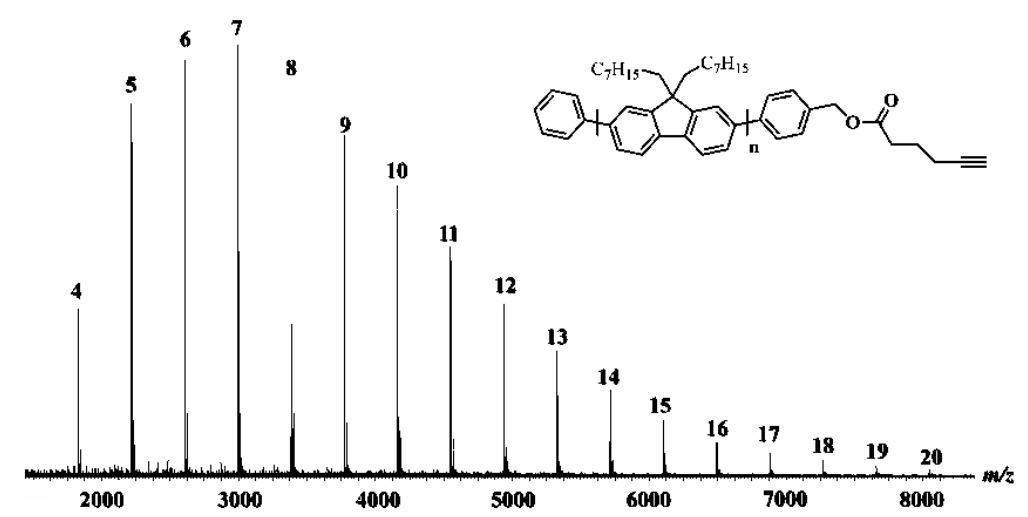

Figure 4. MALDI-ToF spectrum of $\mathbf{P 4}$ (degree of polymerization is assigned on the top of each signal)

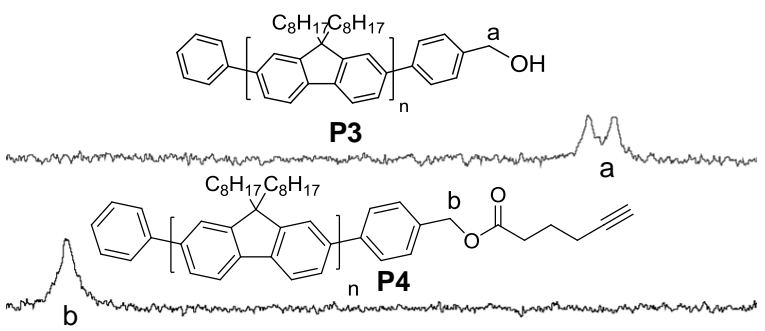
5.2
$5.1 \quad 5.0$
4.9

$\begin{array}{llll}4.8 & 4 & & \\ 4 & 4.7\end{array}$

Figure 5. Complete conversion of $\mathbf{P 3}$ to $\mathbf{P 4}$ via a postpolymerization reaction. 
Table 2. GPC analysis of $\mathbf{P 3}$ and $\mathbf{P 4}$

\begin{tabular}{ccc}
\hline Polymer & $\begin{array}{c}\overline{\boldsymbol{M}}_{\mathbf{n}} \\
(\mathbf{k g} / \mathbf{m o l})\end{array}$ & Đ \\
\hline P3 & 8.1 & 1.2 \\
P4 & 8.0 & 1.2
\end{tabular}

\subsection{Synthesis and characterization of graft copolymers}

To graft $\mathbf{P 4}$ to the P2-x backbone, the copper(I) catalyzed acetylene-azide cycloaddition (CuAAC) click reaction (Scheme 5) was selected. ${ }^{26-28}$ The high efficiency of this reaction already proved to be very efficient in the past. A complete grafting of the block with the hexylazide sidechains was aimed for. The reaction was monitored via GPC. Unreacted PF polymer was removed by preparative GPC.

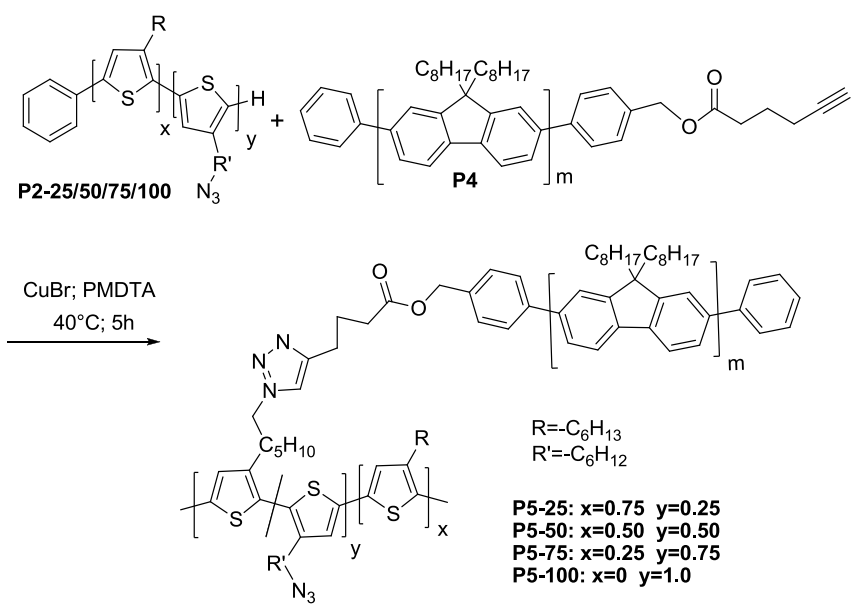

Scheme 5. Grafting of $\mathbf{P 4}$ to $\mathbf{P 2 - 2 5 / 5 0 / 7 5 / 1 0 0}$ to form toothbrush polymers $\mathbf{P 5 - 2 5 / 5 0 / 7 5 / 1 0 0}$.

\subsection{GPC and ${ }^{1} \mathrm{H}-\mathrm{NMR}$ analysis}

Via GPC, analysis of the molar mass of the toothbrush polymers P5-x was carried out. The chromatograms were recorded at two different wavelengths (440 and $380 \mathrm{~nm}$ ) corresponding to the absorption maxima of the polythiophene backbone and the polyfluorene sidechains, respectively (Figure 6). As can be seen from Table 3 and Spectra in SI, $\bar{M}_{\mathrm{n}}$ values for both 
wavelengths were measured similar, ruling out the presence of significant amounts of residual homopolymers.

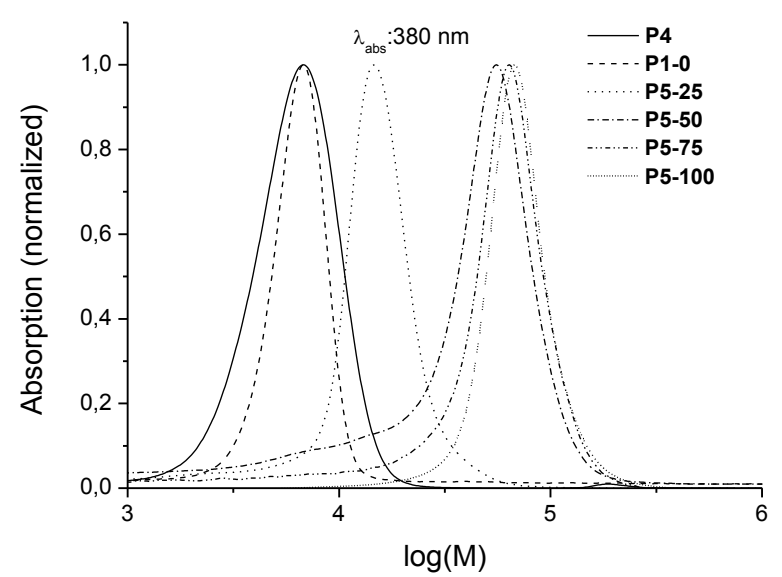

Figure 6: Chromatograms of homopolymers P1-0/P4 and toothbrush copolymers P525/50/75/100.

Table 3. $\overline{\mathrm{M}}_{\mathrm{n}}$ and $Đ$ values of the brush copolymers determined via absorption at 2 different wavelengths: 380 and $440 \mathrm{~nm}$.

\begin{tabular}{cccc}
\hline Polymer & $\begin{array}{c}\overline{\boldsymbol{M}}_{\mathbf{n}}(\mathbf{k g} / \mathbf{m o l}) \\
\boldsymbol{\lambda}=\mathbf{3 8 0} \mathbf{~ n m}\end{array}$ & $\begin{array}{c}\overline{\boldsymbol{M}}_{\mathbf{n}}(\mathbf{k g} / \mathbf{m o l}) \\
\boldsymbol{\lambda}=\mathbf{4 4 0} \mathbf{~ n m}\end{array}$ & Đ \\
\hline P5-25 & 16.4 & 16.7 & 1.1 \\
P5-50 & 49.4 & 51.6 & 1.3 \\
P5-75 & 63.9 & 64.7 & 1.2 \\
P5-100 & 70.0 & 70.2 & 1.1
\end{tabular}

Also ${ }^{1} \mathrm{H}-\mathrm{NMR}$ spectra were recorded to elucidate the structure of the polymers. ${ }^{1} \mathrm{H}-\mathrm{NMR}$ spectra of P1-0, P4 and P5-25 are shown in Figure 7. For this toothbrush copolymers, the poly(fluorene) and poly(thiophene) content are both clearly visible. 


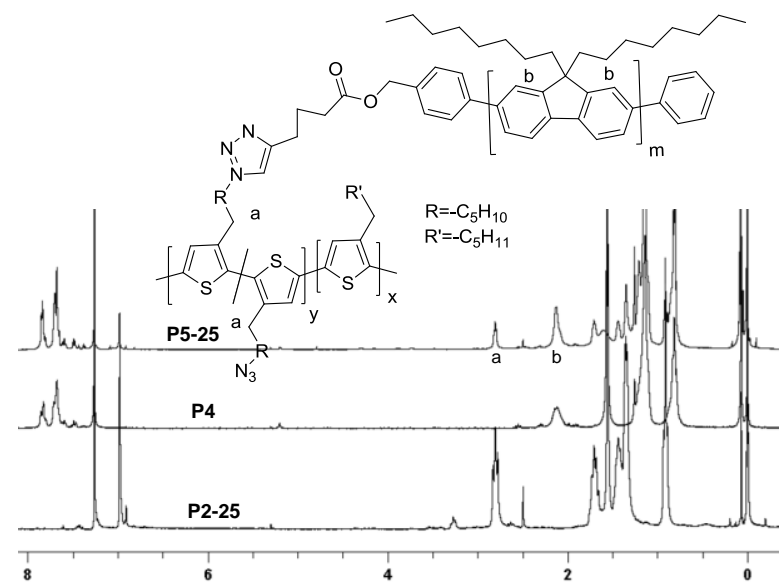

Figure 7. Overlaid ${ }^{1} \mathrm{H}-\mathrm{NMR}$ spectra of brush copolymers P5-25 and homopolymers P4 and P10

The ${ }^{1} \mathrm{H}-\mathrm{NMR}$ data were then used to determine the grafting percentage. This was done using the protons a of the polythiophene backbone and protons b of the polyfluorene sidechains. As the polyfluorene sidechain contains 15 units, the grafting percentage equals:

grafting $\%=\frac{\frac{b}{4 \cdot 15}}{\frac{a}{2}}$

Values of 8\% and 25\% were obtained for P5-25 and P5-50 (Table 4). For P5-25, this nearly equals the percentage of the length of the Y block and therefore this block is completely grafted. However, for P5-50, the percentage is only half of the percentage of the length of the Y block. For P5-75/100, the signals due to the P3AT segment are barely visible because of its low content and the spectra resemble the spectrum of pure PF. Therefore, the grafting percentage could not be calculated relying on ${ }^{1} \mathrm{H}-\mathrm{NMR}$ spectra. In order to determine the grafting percentage, UVvis spectra were exploited.

\subsection{UV-vis spectroscopy}

The optical properties and self-assembly of the homo and graft copolymers were studied by recording UV-vis spectra in mixtures of good solvent - chloroform - and poor solvent methanol. Starting from pure chloroform solutions (Figure 9), the methanol content was gradually increased in steps of 10\% (see SI). Only for P1-25 and P1-50, absorption due to the P3AT content is still somewhat visible, while for P1-75 and P1-100 the UV-vis spectrum 
strongly resembles the spectrum of the polyfluorene sidechain (P4). Both homopolymers start to aggregate from a 70/30 chloroform/methanol mixture (see SI). For the polyfluorene homopolymer, this is visible by appearance of an extra peak around $440 \mathrm{~nm}$, while for polythiophene it is visible by the redshift of the signal. ${ }^{29}$ The brush copolymers P5-50/75/100, however, only start to aggregate from a 60\% chloroform solution and P5-25 only from a 50\% mixture (see SI). This means that the reduced freedom of motion due to covalent attachment to the P3AT backbone complicates the aggregation of the polyfluorene sidechains. Note that the vibronic fine-structure of the P3AT is not present, indicating that the P3ATs, also the X-block, does self-assemble.

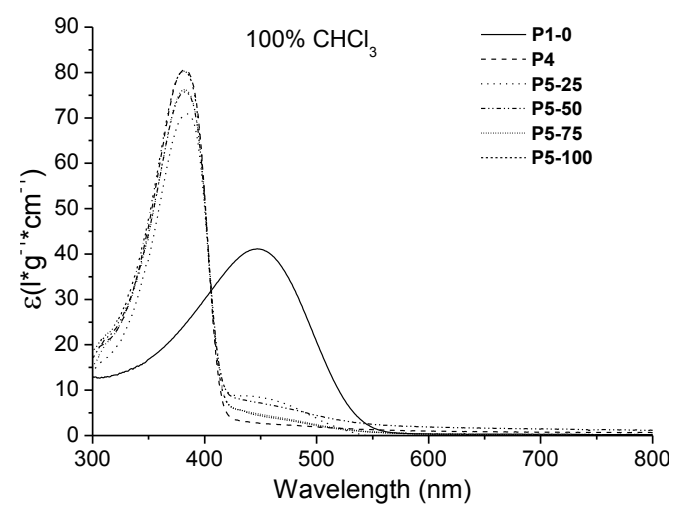

Figure 9. UV-vis spectra of the homopolymers P1-0 and P4 and brush copolymer P525/50/75/100.

As the backbone and sidechains are completely dissolved in pure chloroform and behave independent of each other, it is possible to determine the mass \% of P3AT and polyfluorene for each brush copolymer injecting the extinction coefficients for the homo and graft copolymers in pure chloroform in the next formula:

$\operatorname{mass} \%(\mathrm{P} 3 \mathrm{AT})=\frac{\varepsilon(\mathbf{P 5}-\mathbf{x})-\varepsilon(\mathbf{P 4})}{\varepsilon(\mathbf{P 1}-\mathbf{0})-\varepsilon(\mathbf{P 4})}$

Because the DP of the backbone and the sidechains are known, the average number of PF sidechains for each P3AT backbone can be calculated and, as a consequence, also the grafting percentage (Table 4) can be estimated. 
Table 4. Mass and graft percentages of the brush (co)polymers.

\begin{tabular}{ccccc}
\hline Polymer & $\begin{array}{c}\text { PF wt\% } \\
\text { (UV-vis) }\end{array}$ & $\begin{array}{c}\text { P3AT wt\% } \\
\text { (UV-vis) }\end{array}$ & $\begin{array}{c}\text { graft\% } \\
\text { (UV-vis) }\end{array}$ & $\begin{array}{c}\text { graft\% } \\
\text { (NMR) }\end{array}$ \\
\hline P5-25 & 74 & 26 & 7 & 8 \\
P5-50 & 91 & 9 & 24 & 25 \\
P5-75 & 94 & 6 & 34 & $/$ \\
P5-100 & 96 & 4 & 56 & $/$
\end{tabular}

when the graft $\%$ determined via UV-vis and ${ }^{1} \mathrm{H}-\mathrm{NMR}$ data are compared, a good agreement between the values for P5-25 and P5-50 is observed. While theoretically $8 \%$ and $49 \%$ (Table 1) could be grafted, P5-25 is completely grafted while for P5-50 only half of the Y block is grafted. This trend continues for P5-75 and P5-100, where the grafting percentage is approximately half the value of what is theoretically possible. This observation can be explained by steric hindrance.

\subsection{Fluorescence spectroscopy}

Chloroform solutions of the homo and brush polymers were excited at $380 \mathrm{~nm}$, the $\lambda_{\text {max,abs }}$ of poly(fluorene), and emission spectra were recorded (Figure 10). As the $\lambda_{\max , \mathrm{em}}$ of PF (420 nm) is close and somewhat higher in energy than the $\lambda_{\text {max,abs }}$ of P3AT (440 nm), energy transfer is expected to occur. ${ }^{30-34}$ The spectra are corrected by dividing the values by the absorbance at the excitation wavelength.

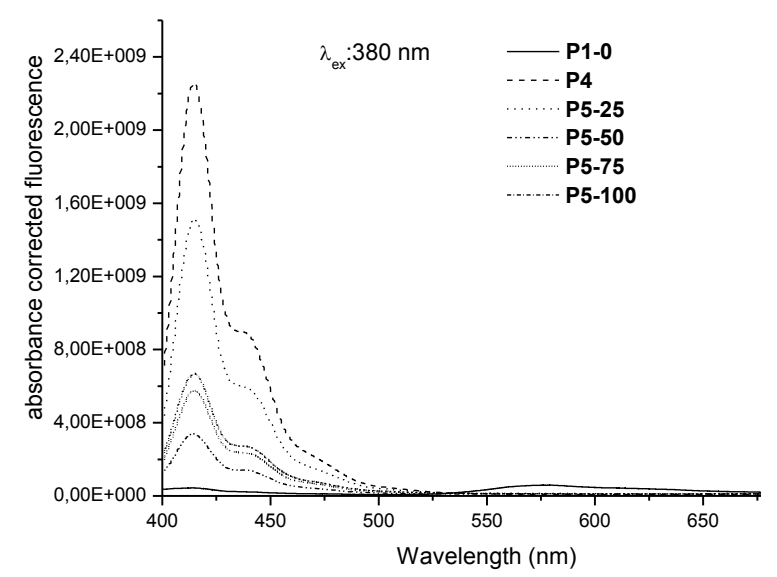

Figure 10. Absorption corrected fluorescence spectra of homopolymers P1-0 and P4 and brush copolymers P5-25/50/75/100. 
Taking into account the different weight percentage of P3AT and PF for the toothbrush copolymers and the fact that both absorb at the excitation wavelength with a different extinction coefficient, it is possible to calculate the fluorescence in absence of energy transfer. Taking the difference between experimental and calculated values and subsequent division by the calculated values without considering transfer, it is possible to get an indication of the extent of percentage of energy transfer. The obtained values (Table 5) show that transfer is indeed occurring. While the loss in fluorescence for the polyfluorene sidechains remains quite constant, except for P5-25, there is an increase in fluorescence of the poly(thiophene) backbone compared to what is expected on basis of the diminishing weight percentage of polythiophene without considering energy transfer. For example, P5-50 with one third of the weight percentage of PT compared to P5-25 (Table 4) has around 3 times higher percentage of transfer to the P3AT backbone (Table 5).

Table 5. Percentual difference in fluorescence between the experimental obtained values and the theoretical calculated fluorescence without considering energy transfer.

\begin{tabular}{lcccc}
\hline & \multicolumn{4}{c}{$\Delta$ fluorescence (\%) } \\
\hline P5-25 & P5-50 & P5-75 & P5-100 \\
PF-sidechains & -0.13 & -0.82 & -0.69 & -0.73 \\
P3AT backbone & 1.8 & 6.2 & 10.8 & 12.7 \\
If we compare this values to the energy transfer in the previous reported polymer systems where \\
the polyfluorene polymers were randomly distributed over the polymer backbone, in case of \\
graft copolymers, the transfer is more than one order of magnitude lower. ${ }^{12}$ The previous \\
reported polymers P5 and P6 can be correlated to P5-25 and P5-50 respectively, in terms of \\
their grafting percentage of $10 \%$ and 17\%.
\end{tabular}

\section{Conclusions}


The synthesis of conjugated toothbrush copolymers is reported for the first time. It is also the first report of conjugated graft copolymers with backbone and sidechains of different chemical nature for which both are prepared in a controlled way. The backbone consisted of a poly(thiophene) block copolymer prepared via KCTCP. The polyfluorene sidechains, prepared in a controlled way via Suzuki-Miyaura coupling using a protocol with a stable precatalyst, were connected to the backbone using the $\mathrm{CuAAC}$ click reaction. By removing non-reacted polyfluorene, clean monomodal GPC spectra were recorded. The Y blocks that can be grafted forming the brush part amount to percentages of $0,8,49,73$ and $100 \%$ of the total units. The corresponding total grafting percentages obtained are $0,8,25,34$ and $56 \%$. This means that only P5-25 is completely grafted, while all others are only grafted for a percentage that is half of what is theoretical possible due to steric constraints. UV-vis solvatochromism experiments indicated that aggregation of the polyfluorene is compromised due to their covalent attachment to the poly(thiophene) backbone. As the emission spectrum of the sidechains overlaps with the absorption of the backbone, the system is very suitable for the study of energy transfer. The occurrence of energy transfer was demonstrated with increasing efficiency for higher grafting percentages. However, the transfer seems much less efficient as for analog systems with the same grafting percentage but with the sidechains randomly distributed over the backbone instead of being packed on one small segment.

\section{Acknowledgements}

We are grateful to the Onderzoeksfonds KU Leuven/Research Fund KU Leuven and the Fund for Scientific Research (FWO-Vlaanderen) for financial support. JS is grateful to IWT for a doctoral fellowship. The UMONS lab is grateful to the FRS-FNRS for financial support for the acquisition of the Waters QToF Premier mass spectrometer.

\section{Abbreviations}


CuAAC (copper(I) catalyzed acetylene-azide cycloaddition); DCC ( $N, N$ '-dicyclohexyl carbodiimide); DP (degree of polymerization); DMAP ( $N, N^{\prime}$-4-dimethylaminopyridine); GRIM (Grignard metathesis); KCTP (Kumada condensative catalyst transfer polymerization); P3AT (poly(3-alkylthiophene); PF (polyfluorene)

\section{References}

1 R. Wang, W.-Z. Wang, G.-Z. Yang, T. Liu, J. Yu and Y. Jiang, J. Polym. Sci. Part A Polym. Chem., 2008, 46, 790-802.

2 P. Taranekar, Q. Qiao, H. Jiang, I. Ghiviriga, K. S. Schanze and J. R. Reynolds, J. Am. Chem. Soc., 2007, 129, 8958-9.

3 M. Vanjinathan, H.-C. Lin and A. S. Nasar, J. Polym. Sci. Part A Polym. Chem., 2012, 50, 3806-3818.

4 Z. Li, S. Ye, Y. Liu, G. Yu, W. Wu, J. Qin and Z. Li, J. Phys. Chem. B, 2010, 114, 9101-8.

5 T. Kim, D.-K. Park and T. Ahn, Mol. Cryst. Liq. Cryst., 2012, 567, 125-131.

6 Y. Han, M. Sun, Z. Fei and Z. Bo, Chinese Sci. Bull., 2008, 53, 2770-2776.

7 J. Chen, H. Peng, C. C. W. Law, Y. Dong, J. W. Y. Lam, I. D. Williams and B. Z. Tang, Macromolecules, 2003, 36, 4319-4327.

8 X. Wu, H. Li, B. Xu, H. Tong and L. Wang, Polym. Chem., 2014, 5, 4521-4525.

9 J. Wang, C. Lu, T. Mizobe, M. Ueda, W.-C. Chen and T. Higashihara, Macromolecules, 2013, 46, 1783-1793.

10 D. F. Zeigler, K. A. Mazzio and C. K. Luscombe, Macromolecules, 2014, 47, 50195028.

11 J. Steverlynck, P. Leysen and G. Koeckelberghs, J. Polym. Sci. Part A Polym. Chem., 2015, 53, 79-84. 
12 J. Steverlynck, A. De Cattelle, J. De Winter, P. Gerbaux and G. Koeckelberghs, J. Polym. Sci. Part A Polym. Chem., 2016, 54, 1252-1258.

13 C. S. Fischer, C. Jenewein and S. Mecking, Macromolecules, 2015, 48, 483-491.

14 D. Tang, X. Jiang, H. Liu, C. Li and Y. Zhao, Polym. Chem., 2014, 5, 4679.

15 W. Zhang, Y. Li, L. Liu, Q. Sun, X. Shuai, W. Zhu and Y. Chen, Biomacromolecules, 2010, 11, 1331-1338.

16 A. P. Martinez, Z. Cui, C. Hire, T. A. P. Seery and D. H. Adamson, Macromolecules, $2015,48,4250-4255$.

17 M. Tong, X. An, W. Pan, H. Liu and Y. Zhao, Polym. Chem., 2016, 7, 2209-2221.

18 A. Smeets, K. Van den Bergh, J. De Winter, P. Gerbaux, T. Verbiest and G. Koeckelberghs, Macromolecules, 2009, 42, 7638-7641.

19 M. Verswyvel, F. Monnaie and G. Koeckelberghs, Macromolecules, 2011, 44, 94899498.

20 L. Zhai, R. L. Pilston, K. L. Zaiger, K. K. Stokes and R. D. McCullough, Macromolecules, 2003, 36, 61-64.

21 H.-H. Zhang, W. Peng, J. Dong and Q.-S. Hu, ACS Macro Lett., 2016, 5, 656-660.

22 H.-H. Zhang, J. Dong and Q.-S. Hu, European J. Org. Chem., 2014, 2014, 1327-1332.

23 H.-H. Zhang, C.-H. Xing, G. B. Tsemo and Q.-S. Hu, ACS Macro Lett., 2013, 2, 1013.

24 A. J. DeAngelis, P. G. Gildner, R. Chow and T. J. Colacot, J. Org. Chem., 2015, 80, 6794-6813.

25 Q. Wang, Y. Qu, H. Tian, Y. Geng and F. Wang, Macromolecules, 2011, 44, 12561260.

26 V. V Rostovtsev, L. G. Green, V. V Fokin and K. B. Sharpless, Angew. Chem. Int. Ed. Engl., 2002, 41, 2596-9.

27 H. C. Kolb, M. G. Finn and K. B. Sharpless, Angew. Chemie Int. Ed., 2001, 40, 2004- 
2021.

28 Y. Qiao, R. Ferebee, B. Lee, I. Mitra, N. A. Lynd, J. Hayat, G. E. Stein, M. R.

Bockstaller and C. Tang, Macromolecules, 2014, 47, 6373-6381.

29 C. E. Halkyard, M. E. Rampey, L. Kloppenburg, S. L. Studer-Martinez and U. H. F. Bunz, Macromolecules, 1998, 31, 8655-8659.

30 G. Tu, H. Li, M. Forster, R. Heiderhoff, L. J. Balk, R. Sigel and U. Scherf, Small, 2007, 3, 1001-1006.

31 A. Gutacker, S. Adamczyk, A. Helfer, L. E. Garner, R. C. Evans, S. M. Fonseca, M. Knaapila, G. C. Bazan, H. D. Burrows and U. Scherf, J. Mater. Chem., 2010, 20, 14231430.

32 A. Gutacker, N. Koenen, U. Scherf, S. Adamczyk, J. Pina, S. M. Fonseca, A. J. M. Valente, R. C. Evans, J. Seixas de Melo, H. D. Burrows and M. Knaapila, Polymer, 2010, 51, 1898-1903.

33 M. Knaapila, R. C. Evans, A. Gutacker, V. M. Garamus, M. Torkkeli, S. Adamczyk, M. Forster, U. Scherf and H. D. Burrows, Langmuir, 2010, 26, 5056-5066.

34 B. Liu and G. Barzan, Conjugated Polyelectrolytes: Fundamentals and Applications, WILEY-VCH Verlag GmbH, First Edit., 2013. 
Joost Steverlynck, Julien De Winter, Pascal Gerbaux, Guy Koeckelberghs*

Synthesis and energy transfer in original poly(3-alkylthiophene)-g-poly(fluorene) toothbrush copolymers

A series of P3AT-g-PF brush copolymers are prepared by grafting PF sidechains to different P3AT blockcopolymers. UV-vis spectra are recorded to probe the effect of the covalent attachment of the PF sidechains on their aggregation. Fluorescence spectra in pure chloroform are measured and subsequent calculations are performed to study the energy funneling from the sidechains to the backbone.

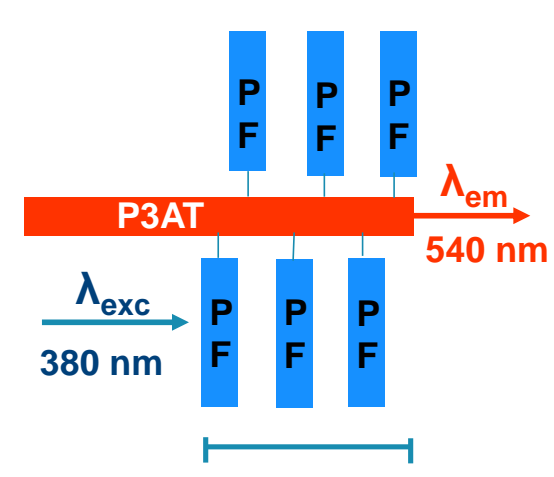

$Y=0,8,49,71,100 \%$ 